\title{
Review Article \\ Immunomodulatory Effects of Drugs for Effective Cancer Immunotherapy
}

\author{
Maiko Matsushita (D) and Mai Kawaguchi \\ Division of Clinical Physiology and Therapeutics, Keio University, Faculty of Pharmacy, 1-5-30, Shiabakoen, Minato-Ku, Tokyo, Japan \\ Correspondence should be addressed to Maiko Matsushita; matsushita-mk@pha.keio.ac.jp
}

Received 31 August 2018; Accepted 10 October 2018; Published 25 October 2018

Guest Editor: Hailun Wang

Copyright ( 2018 Maiko Matsushita and Mai Kawaguchi. This is an open access article distributed under the Creative Commons Attribution License, which permits unrestricted use, distribution, and reproduction in any medium, provided the original work is properly cited.

\begin{abstract}
Recent advances in cancer immunotherapy, including immune checkpoint inhibitors or adoptive T cell therapies, have contributed to better outcomes in cancer patients. However, there are still many cancers with no cure. Therefore, combinations of several treatment strategies are being explored, and enhancing anticancer immunity will play an important role to combat the disease. There have been several reports on the immune-modulatory effects of commonly used drugs, namely, statin, metformin, and angiotensin receptor blockers (ARBs), which suggest that these drugs could enhance immunity against cancer cells. Other anticancer drugs, such as anthracyclines, thalidomides, lenalidomides, and hypomethylating drugs, could also strengthen the immune system to attack cancer cells at a relatively low dose. Hence, these drugs might contribute to better outcomes in cancer patients.
\end{abstract}

\section{Introduction}

Immune system dysfunction is related to many diseases, including inflammatory diseases, autoimmune diseases, infectious diseases, atherosclerosis, and cancer [1-5]. Several drugs that directly target the immune system have been developed for the treatment of these disorders. For example, immune checkpoint inhibitors (ICIs) have greatly improved the outcome of various cancers by altering patients' immunesuppressive status and enhancing antitumor immunity [68]. However, even ICIs are ineffective in the treatment and cure of certain cancers. Therefore, new strategies to enhance the efficacy of these treatments are needed. Moreover, ICIs and many of the other targeted anticancer therapies consist of monoclonal antibodies, which make them highly expensive.

On the other hand, immunomodulatory effects have been described for several small molecular drugs, which have been used for a long time to treat common diseases, including hyperlipidemia, diabetes, and hypertension [9-11]. These drugs are cost-effective and could be used safely, as their adverse reactions are well known. If immunomodulatory effects of these previously approved drugs are clearly established, it might be possible to enhance the effects of conventional cancer therapy by combinatorial use of these drugs $[12,13]$. In this review, we discuss drugs that have been reported to elicit immunomodulatory effects in addition to their original pharmacological effects.

We searched previously published literature for papers on immunomodulatory function of drugs using PubMed (https://www.ncbi.nlm.nih.gov/pubmed/). By using "immunomodulating" and "drugs" as search words, we obtained 3433 papers (August 2018). We excluded papers with monoclonal antibodies and previously approved immunosuppressive drugs, such as corticosteroids. We classified the remaining drugs, obtained in the search, based on their effects on cytokines (Table 1), immune cells ( $\mathrm{T}$ cells, B cells, and antigen presenting cells; Table 2), and immunerelated signaling pathways (nuclear factor-kappa B: NF-kB, Signal Transducers and Activator of Transcription: STAT, Peroxisome Proliferator-Activated Receptor $\gamma$ : PPARl $\gamma$, Extracellular Signal-Regulated Kinase: ERK, mechanistic target of rapamycin: mTOR, and AMP-activated protein kinase: AMPK; Table 3).

To ascertain drugs that could be used for cancer treatment, we selected the drugs that have been reported to have anticancer effects by enhancing immunological responses to cancer cells. Three drugs approved for treatment of 


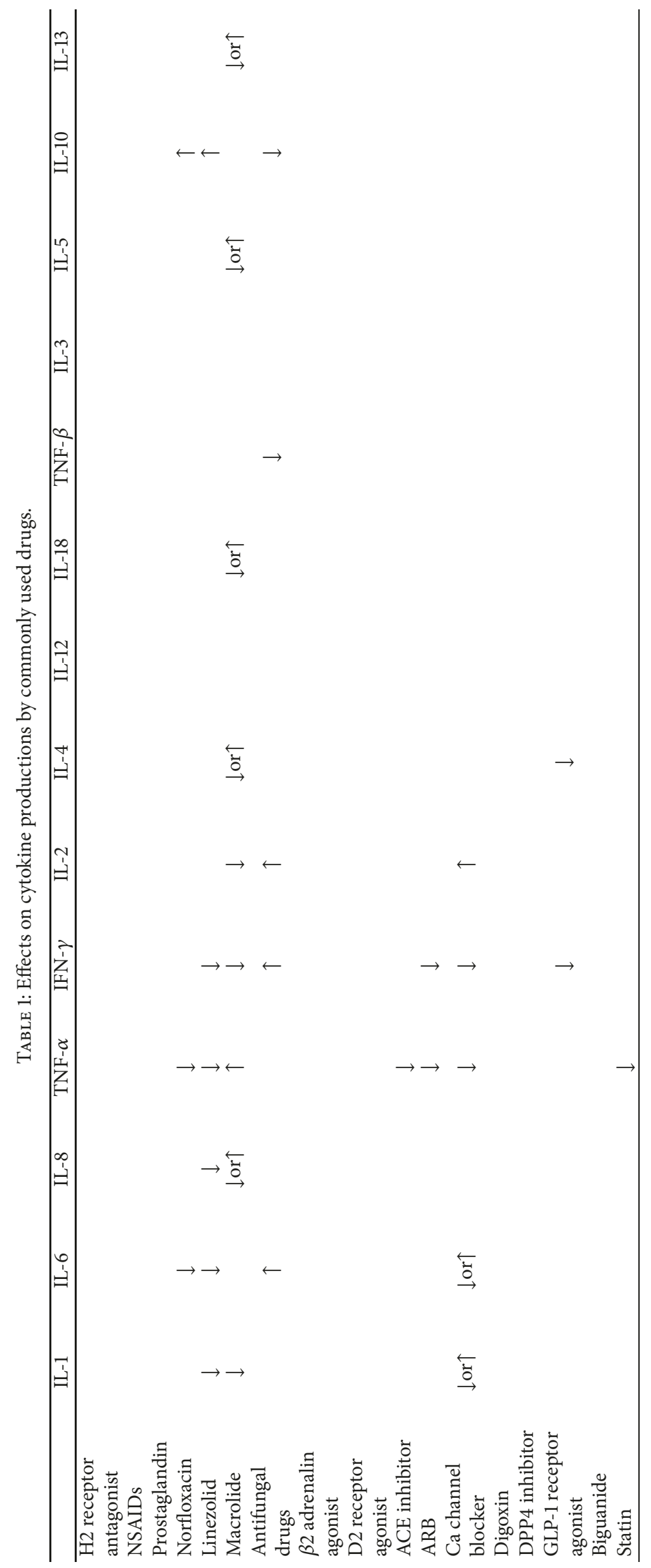


TABLE 2: Effects on immune cells by commonly used drugs.

\begin{tabular}{|c|c|c|c|c|c|c|c|c|c|c|}
\hline & $\mathrm{T}$ celll & Th1 & Treg & Th17 & MDSC & CTL & B cell & $\mathrm{NK}$ & $\mathrm{CD} 4$ & CD8+TIL \\
\hline $\begin{array}{l}\mathrm{H} 2 \text { receptor } \\
\text { antagonist }\end{array}$ & $\uparrow$ & & & & & & & & & \\
\hline NSAIDs & & & & & & & & & $\uparrow$ & \\
\hline \multicolumn{11}{|l|}{ Prostaglandin } \\
\hline \multicolumn{11}{|l|}{ Norfloxacin } \\
\hline \multicolumn{11}{|l|}{ Linezolid } \\
\hline Macrolide & & & & & & & & & $\uparrow$ & \\
\hline \multicolumn{11}{|l|}{$\begin{array}{l}\text { Antifungal } \\
\text { drugs }\end{array}$} \\
\hline \multicolumn{11}{|l|}{$\begin{array}{l}\beta 2 \text { adrenalin } \\
\text { agonist }\end{array}$} \\
\hline \multicolumn{11}{|l|}{$\begin{array}{l}\text { D2 receptor } \\
\text { agonist }\end{array}$} \\
\hline ACE inhibitor & $\downarrow$ & & & & & & & & & \\
\hline ARB & & & & & & $\downarrow$ & & & & \\
\hline \multicolumn{11}{|l|}{$\begin{array}{l}\text { Ca channel } \\
\text { blocker }\end{array}$} \\
\hline Digoxin & & & & $\downarrow$ & & & & & & \\
\hline DPP4 inhibitor & & & $\uparrow$ & & & & & & $\downarrow$ & \\
\hline Biguanide & & & & & & & & & & $\uparrow$ \\
\hline Statin & $\downarrow$ & $\downarrow$ & $\uparrow$ & $\downarrow$ & & & & $\downarrow$ & & \\
\hline
\end{tabular}

TABLE 3: Effects on gene expressions in immune-related signaling pathways by commonly used drugs.

\begin{tabular}{|c|c|c|c|c|c|c|}
\hline & $N F-\kappa B$ & STAT & PPAR1 $\gamma$ & ERK & mTOR & AMPK \\
\hline \multicolumn{7}{|l|}{$\begin{array}{l}\mathrm{H} 2 \text { receptor } \\
\text { antagonist }\end{array}$} \\
\hline \multicolumn{7}{|l|}{ NSAIDs } \\
\hline \multicolumn{7}{|l|}{ Prostaglandin } \\
\hline \multicolumn{7}{|l|}{ Norfloxacin } \\
\hline Linezolid & & $\downarrow$ & & & & \\
\hline Macrolide & $\downarrow$ & & & $\downarrow$ & & \\
\hline \multicolumn{7}{|l|}{$\begin{array}{l}\text { Antifungal } \\
\text { drugs }\end{array}$} \\
\hline \multicolumn{7}{|l|}{$\begin{array}{l}\beta 2 \text { adrenalin } \\
\text { agonist }\end{array}$} \\
\hline \multicolumn{7}{|l|}{$\begin{array}{l}\text { D2 receptor } \\
\text { agonist }\end{array}$} \\
\hline \multicolumn{7}{|l|}{ ACE inhibitor } \\
\hline \multicolumn{7}{|l|}{$\mathrm{ARB}$} \\
\hline $\begin{array}{l}\text { Ca channel } \\
\text { blocker }\end{array}$ & $\downarrow$ or $\uparrow$ & & & & & \\
\hline \multicolumn{7}{|l|}{ Digoxin } \\
\hline DPP4 inhibitor & $\uparrow$ & & & & & \\
\hline Biguanide & & & & & $\downarrow$ & $\uparrow$ \\
\hline Statin & & $\downarrow$ & $\uparrow$ & $\uparrow$ & & \\
\hline Cannabidiol & & & & & & \\
\hline
\end{tabular}


common diseases (statin, metformin, and angiotensin receptor blocker) and three categories of anticancer drugs that show immunomodulatory effects (thalidomide and its derivatives, anthracyclines or other chemotherapeutic drugs, and demethylating agents) are discussed further for their anticancer property via immunological mechanisms.

\section{Immunomodulatory Effects of Drugs Used for Treating Common Diseases}

2.1. Statins. Statins have been used by millions of people for lowering blood lipids to prevent coronary heart disease [14]. They inhibit hydroxymethylglutaryl (HMG) CoA reductase in the cholesterol biosynthesis pathway. In addition to their cholesterol-lowering effects, many studies have shown that statins also exhibit immune-modulatory properties through mevalonate-independent and -dependent pathways [15]. They inhibit the activity of Ras and Rho family GTPases, which regulate various cellular functions, such as cell death, metastasis, and immune reactions [16-18]. Statins affect the immune cells by decreasing the production of inflammatory cytokines and activating $\mathrm{CD}^{+} \mathrm{T}$ cells [19]. Sarrabayrouse et al. have also reported that statin treatment induces the expression of CD80 and CD86 in melanoma cells by upregulating their gene expression through transcriptional factors controlled by Rho proteins [20]. In fact, clinical studies have confirmed the role of statins in preventing several types of cancer [21-23]. These data suggest that statins might be useful for enhancing the immunity against cancer cells.

2.2. Metformin. Metformin is one of the widely used antidiabetic drugs synthesized from the plant Galega officinalis, which lowers blood glucose level by suppressing hepatic glucose production in patients with type 2 diabetes [24]. It inhibits $\mathrm{NADH}$ : ubiquinone oxidoreductase located in the mitochondrial membrane, leading to the activation of $5^{\prime}$-AMP-activated protein kinase (AMPK) and suppression of gluconeogenesis. AMPK-independent pathway also contributes to its pharmacological actions [25]. In addition to its antihyperglycemic effects, there are many reports of its role in immune response. It has been shown that metformin enhances the number and function of tumor-infiltrating lymphocytes (TILs) [26]. Pereira et al. have reported that metformin exerts strong immunomodulatory effects and contributes to reduced lung metastasis of melanoma cells [27]. Cha et al. have shown that metformin reduces the stability and membrane localization of programmed deathligand 1 (PD-L1) and contributes to the enhancement of cytotoxic T lymphocyte (CTL) activity against cancer cells [28]. Metformin also exerts anti-inflammatory effects [29, 30]. It was recently reported that these effects might be related to the alteration of gut microbiota [31]. These results suggest that metformin can be used for the treatment of cancer.

2.3. Angiotensin Receptor Blockers (ARBs). Renin-angiotensin system mainly controls blood pressure; however, cancer cells and their microenvironment also express renin and angiotensin, which play a pathophysiological role in cancer development [32]. Several clinical studies have demonstrated that taking ARBs could decrease the risk of developing cancers $[33,34]$. In vitro and in vivo studies have further revealed that these anticancer effects of ARB include direct suppression of cancer growth and increase of antitumor immunity [35-38]. Nakamura et al. showed that administration of $\mathrm{ARB}$ to colon cancer-bearing mice induced the expansion of cancer-specific CTLs and reduced the levels of immune-suppressive cytokines, interleukin-6 (IL-6), IL-10, vascular endothelial cell factor, and arginase in the tumor microenvironment [39]. They demonstrated that combination therapy with ARB and anti PD-L1 antibody significantly reduced tumor size, suggesting that this therapy is also useful in clinical setting.

\section{Immunomodulating Effects of Anticancer Drugs}

3.1. Thalidomide, Lenalidomide, and Pomalidomide. Thalidomide, and its derivatives, lenalidomide, and pomalidomide are used as key drugs in the treatment of multiple myeloma, which is a plasma cell neoplasm [40-42]. Thalidomide first made headlines for its direct tumoricidal effects on myeloma cells by causing cell cycle arrest and also its antiangiogenic properties. Later, it was classified as an immunomodulatory drug (IMiD) owing to its immunological effects [43]. IMiDs stimulate $\mathrm{T}$ cells and natural killer T (NKT) cells to secrete IL- 2 and interferon- $\gamma$, leading to NK cell activation and inhibition of regulatory $\mathrm{T}$ cells. As a result, myelomaspecific immunity is amplified [44-46]. The FDA has recently approved lenalidomide for maintenance therapy of posttransplant myeloma patients, considering that lenalidomide can suppress the residual myeloma cells.

\subsection{Anthracyclines and Other Chemotherapeutic Drugs.} Some of conventional anticancer drugs, such as anthracyclines or alkylating agents, have been reported to cause induction of immunomodulatory effects on various cancer cells by enhancing the cell surface expression of calreticulin (CRT) followed by the release of high mobility group box 1 (HMGB1), ATP, annexin A1, and type I interferon from cancer cells [47-50]. The dendritic cells (DCs) then recognize CRT, HMGB1, and ATP through CD91, Toll-like receptor 4 , and P2X purinoreceptor 7 , respectively, and take up the cancer cells. This series of events is called immunogenic cell death (ICD) [51-53]. Mouse immunization experiments using cancer cells pretreated with chemotherapeutic drugs, such as doxorubicin or mitoxantrone, have shown effective cancer regression through CRT expression and HMGB1 secretion [54-56]. These observations were further confirmed by clinical data, which have indicated that CRT expression is important for the improvement of disease outcome in cancer patients [57]. These results suggest that some of the chemotherapeutic drugs not only kill cancer cells directly but also strengthen patients' immune reactions against cancer cells, thereby contributing to the eradication of cancer cells. Moreover, other types of anticancer drugs, 
such as epidermal growth factor receptor inhibitors, also elicit immune reactions against cancer cells through ICD [58]. ICD inducers, especially cyclophosphamide, are now expected to enhance the antitumor effects of other immunotherapies, such as cancer vaccines or immune checkpoint inhibitors [59-62].

3.3. Azacitidine and Decitabine. Hypermethylation of tumor suppressor genes in the promoter region and subsequent silencing of these genes is observed in many cancer cells. Hence, hypomethylating agents (HMAs) are expected to be useful in cancer treatment by causing epigenetic modulation of these cancer-related genes [63]. HMAs, such as azacitidine or decitabine, have been approved for the treatment of myelodysplastic syndromes (MDS) and acute myeloid leukemia (AML) [64]. These HMAs are analogues of pyrimidine nucleosides, which are incorporated into RNA or DNA, and they impair DNA methylation by inhibiting DNA methyltransferase $[65,66]$. At the same time, HMAs are known to enhance expression of cancer-specific antigens and MHC molecules, making cancer cells sensitive to killing by CTLs in vitro and in vivo [67-69]. Stone et al. have recently reported that HMAs could also alter immunosuppressive tumor microenvironment by activating type 1 interferon signaling, in combination with another class of epigenetic drugs, histone deacetylase inhibitors [70].

\section{Conclusion}

There have been reports on immunomodulating properties of several commonly used drugs, such as statins, metformin, and ARB, which can be used to treat or prevent cancer via increased antitumor immunity. These drugs can be used safely because of their known adverse reactions and might contribute to cancer treatment. Among anticancer drugs, anthracyclines, IMiDs, and epigenetic drugs not only kill the cancer cells directly, but also enhance the immune system to attack the cancer cells. It will be beneficial to combine these drugs with conventional cancer therapies to achieve better outcomes in cancer patients.

\section{Conflicts of Interest}

The authors report no conflicts of interest.

\section{Acknowledgments}

This work received funding from Keio Gijuku Fukuzawa Memorial Fund for the Advancement of Education and Research. We are thankful to Ms. Saori Matsumoto, Mr. Sho Kashiwazaki, and Mr. Michio Kobori for their suggestions about drugs related to immunogenic cell death. We are also thankful to Dr. Yutaka Hattori and Dr. Daiju Ichikawa for their valuable feedbacks.

\section{References}

[1] D. Latinne and R. Fiasse, "New insights into the cellular immunology of the intestine in relation to the pathophysiology of inflammatory bowel diseases," Acta Gastro-Enterologica Belgica, vol. 69, no. 4, pp. 393-405, 2006.

[2] A. Lombardi, E. Tsomos, S. S. Hammerstad, and Y. Tomer, "Interferon alpha: The key trigger of type 1 diabetes," Journal of Autoimmunity, pp. 30323-30328, 2018.

[3] Q. H. Sam, W. S. Yew, C. J. Seneviratne, M. W. Chang, and L. Y. Chai, "Immunomodulation as Therapy for Fungal Infection: Are We Closer?" Frontiers in Microbiology, vol. 9, 2018.

[4] A. Gisterå and D. F. Ketelhuth, "Lipid-driven immunometabolic responses in atherosclerosis," Current Opinion in Lipidology, pp. 375-380, 2018

[5] D. S. Chen and I. Mellman, "Elements of cancer immunity and the cancer-immune set point," Nature, vol. 541, no. 7637, pp. 321330, 2017.

[6] B. Wahid, A. Ali, S. Rafique et al., "An overview of cancer immunotherapeutic strategies," Immunotherapy, vol. 10, no. 11, pp. 999-1010, 2018.

[7] L. A. Emens, "Breast cancer immunotherapy: Facts and hopes," Clinical Cancer Research, vol. 24, no. 3, pp. 511-520, 2018.

[8] A. Ribas and J. D. Wolchok, "Cancer immunotherapy using checkpoint blockade," Science, vol. 359, no. 6382, pp. 1350-1355, 2018.

[9] T. Fehr, C. Kahlert, W. Fierz et al., "Statin-induced immunomodulatory effects on human T cells in vivo," Atherosclerosis, vol. 175, no. 1, pp. 83-90, 2004.

[10] F. Ursini, E. Russo, G. Pellino et al., "Metformin and Autoimmunity: A "New Deal" of an Old Drug," Frontiers in Immunology, vol. 9, 2018.

[11] J. An, T. Nakajima, K. Kuba, and A. Kimura, "Losartan inhibits LPS-induced inflammatory signaling through a PPAR $\gamma$-dependent mechanism in human THP-1 macrophages," Hypertension Research, vol. 33, no. 8, pp. 831-835, 2010.

[12] A. Popovic, E. M. Jaffee, and N. Zaidi, "Emerging strategies for combination checkpoint modulators in cancer immunotherapy," The Journal of Clinical Investigation, vol. 128, no. 8, pp. 3209-3218, 2018.

[13] P. A. Ott, F. S. Hodi, H. L. Kaufman, J. M. Wigginton, and J. D. Wolchok, "Combination immunotherapy: A road map," Journal for Immuno Therapy of Cancer, vol. 5, no. 1, 2017.

[14] M. Banach, C. Serban, A. Sahebkar et al., "Impact of statin therapy on coronary plaque composition: a systematic review and meta-analysis of virtual histology intravascular ultrasound studies," BMC Medicine, vol. 13, no. 1, 2015.

[15] G. Sarrabayrouse, C. Pich, I. Teiti, and A. F. Tilkin-Mariame, "Regulatory properties of statins and rho gtpases prenylation inhibitiors to stimulate melanoma immunogenicity and promote anti-melanoma immune response," International Journal of Cancer, vol. 140, no. 4, pp. 747-755, 2017.

[16] V.Ziegler, C. Henninger, I. Simiantonakis et al., "Rho inhibition by lovastatin affects apoptosis and DSB repair of primary human lung cells in vitro and lung tissue in vivo following fractionated irradiation," Cell Death \& Disease, vol. 8, no. 8, p. e2978, 2017.

[17] R. Palomino-Morales, S. Perales, C. Torres, A. Linares, and M. J. Alejandre, "Effect of HMG-CoA reductase inhibition on vascular smooth muscle cells extracellular matrix production: Role of RhoA," Current Vascular Pharmacology, vol. 14, no. 4, pp. 345-352, 2016.

[18] M. Islam, S. Sharma, B. Kumar, and T. N. Teknos, "Atorvastatin inhibits RhoC function and limits head and neck cancer metastasis," Oral Oncology, vol. 49, no. 8, pp. 778-786, 2013. 
[19] J. Cote-Daigneault, S. Mehandru, R. Ungaro, A. Atreja, and J.F. Colombel, "Potential Immunomodulatory Effects of Statins in Inflammatory Bowel Disease," Inflammatory Bowel Diseases, vol. 22, no. 3, pp. 724-732, 2015.

[20] G. Sarrabayrouse, C. Pich, R. Moriez et al., "Melanoma cells treated with GGTI and IFN- $\gamma$ allow murine vaccination and enhance cytotoxic response against human melanoma cells," PLoS ONE, vol. 5, no. 2, 2010.

[21] T. J. Vogel, M. T. Goodman, A. J. Li, and C. Y. Jeon, "Statin treatment is associated with survival in a nationally representative population of elderly women with epithelial ovarian cancer," Gynecologic Oncology, vol. 146, no. 2, pp. 340-345, 2017.

[22] A. Wang, H. A. Wakelee, A. K. Aragaki et al., "Protective Effects of Statins in Cancer: Should They Be Prescribed for High-Risk Patients?" Current Atherosclerosis Reports, vol. 18, no. 12, 2016.

[23] P. Desai, R. Wallace, and M. Anderson, "An analysis of the effect of statins on the risk of Non-Hodgkin's Lymphoma in the Women's Health Initiative cohort," Cancer Medicine, vol. 7, no. 5, pp. 2121-2130, 2018.

[24] R. J. Shaw, K. A. Lamia, D. Vasquez et al., "Medicine: the kinase LKB1 mediates glucose homeostasis in liver and therapeutic effects of metformin," Science, vol. 310, no. 5754, pp. 1642-1646, 2005.

[25] G. Rena, D. G. Hardie, and E. R. Pearson, "The mechanisms of action of metformin,” Diabetologia, vol. 60, no. 9, pp. 1577-1585, 2017.

[26] S. Eikawa, M. Nishida, S. Mizukami, C. Yamazaki, E. Nakayama, and H. Udono, "Immune-mediated antitumor effect by type 2 diabetes drug, metformin," Proceedings of the National Acadamy of Sciences of the United States of America, vol. 112, no. 6, pp. 1809-1814, 2015.

[27] F. V. Pereira, A. C. Melo, J. S. Low et al., "Metformin exerts antitumor activity via induction of multiple death pathways in tumor cells and activation of a protective immune response," Oncotarget, vol. 9, no. 40, 2018.

[28] J. Talairach and P. Thournoux, "Metformin promotes antitumor immunity via endoplasmic-reticulum-associated degradation of PD-L1," Mollecular Cell, vol. 71, pp. 606-620, 2018.

[29] D. Di Fusco, V. Dinallo, I. Monteleone et al., "Metformin inhibits inflammatory signals in the gut by controlling AMPK and p38 MAP kinase activation," Clinical Science, vol. 132, no. 11, pp. 1155-1168, 2018.

[30] H. J. Son, J. Lee, S. Y. Lee, and etal., "Metformin attenuates experimental autoimmune arthritis through reciprocal regulation of Th17/Treg balance and osteoclastogenesis," Mediators of Inflammation, vol. 2014, pp. 1-13, 2014.

[31] J. Rodriguez, S. Hiel, and N. M. Delzenne, "Metformin: Old friend, new ways of action-implication of the gut microbiome?" Current Opinion in Clinical Nutrition \& Metabolic Care, vol. 21, no. 4, pp. 294-301, 2018.

[32] A. J. George, W. G. Thomas, and R. D. Hannan, "The reninangiotensin system and cancer: old dog, new tricks," Nature Reviews Cancer, vol. 10, no. 11, pp. 745-759, 2010.

[33] J. Busby, Ú. McMenamin, A. Spence, B. T. Johnston, C. Hughes, and C. R. Cardwell, "Angiotensin receptor blocker use and gastro-oesophageal cancer survival: a population-based cohort study," Alimentary Pharmacology \& Therapeutics, vol. 47, no. 2, pp. 279-288, 2018.

[34] M. Cerullo, F. Gani, S. Y. Chen, J. K. Canner, and T. M. Pawlik, "Impact of Angiotensin Receptor Blocker Use on Overall Survival Among Patients Undergoing Resection for Pancreatic
Cancer," World Journal of Surgery, vol. 41, no. 9, pp. 2361-2370, 2017.

[35] K. Oura, T. Tadokoro, S. Fujihara et al., "Telmisartan inhibits hepatocellular carcinoma cell proliferation in vitro by inducing cell cycle arrest," Oncology Reports, vol. 38, no. 5, pp. 2825-2835, 2017.

[36] S. Fujihara, A. Morishita, K. Ogawa et al., "The angiotensin II type 1 receptor antagonist telmisartan inhibits cell proliferation and tumor growth of esophageal adenocarcinoma via the AMPKalpha/mTOR pathway in vitro and in vivo," Oncotarget, vol. 8, no. 5, 2017.

[37] S. Saikawa, K. Kaji, N. Nishimura et al., "Angiotensin receptor blockade attenuates cholangiocarcinoma cell growth by inhibiting the oncogenic activity of Yes-associated protein," Cancer Letters, vol. 434, pp. 120-129, 2018.

[38] R. Coulson, S. H. Liew, A. A. Connelly, and etal., "The angiotensin receptor blocker, losartan, inhibits mammary tumor development and progression to invasive carcinoma," Oncotarget, vol. 8, pp. 18640-18656, 2017.

[39] K. Nakamura, T. Yaguchi, G. Ohmura et al., "Involvement of local renin-angiotensin system in immunosuppression of tumor microenvironment," Cancer Science, vol. 109, no. 1, pp. 54-64, 2018.

[40] C. S. Chim, S. K. Kumar, R. Z. Orlowski et al., "Management of relapsed and refractory multiple myeloma: Novel agents, antibodies, immunotherapies and beyond," Leukemia, vol. 32, no. 2, pp. 252-262, 2018.

[41] P. Moreau, "How I treat myeloma with new agents," Blood, vol. 130, no. 13, pp. 1507-1513, 2017.

[42] B. Pan and S. Lentzsch, "The application and biology of immunomodulatory drugs (IMiDs) in cancer," Pharmacology \& Therapeutics, vol. 136, no. 1, pp. 56-68, 2012.

[43] J. B. Zeldis, R. Knight, M. Hussein, R. Chopra, and G. Muller, "A review of the history, properties, and use of the immunomodulatory compound lenalidomide," Annals of the New York Academy of Sciences, vol. 1222, no. 1, pp. 76-82, 2011.

[44] K. Luptakova, J. Rosenblatt, B. Glotzbecker et al., "Lenalidomide enhances anti-myeloma cellular immunity," Cancer Immunology, Immunotherapy, vol. 62, no. 1, pp. 39-49, 2013.

[45] H. Quach, D. Ritchie, A. K. Stewart et al., "Mechanism of action of immunomodulatory drugs (IMiDS) in multiple myeloma," Leukemia, vol. 24, no. 1, pp. 22-32, 2010.

[46] A. K. Hsu, H. Quach, T. Tai et al., "The immunostimulatory effect of lenalidomide on NK-cell function is profoundly inhibited by concurrent dexamethasone therapy," Blood, vol. 117, no. 5, pp. 1605-1613, 2011.

[47] M. Obeid, A. Tesniere, F. Ghiringhelli et al., "Calreticulin exposure dictates the immunogenicity of cancer cell death," Nature Medicine, vol. 13, no. 1, pp. 54-61, 2007.

[48] J. W. Hodge, C. T. Garnett, B. Farsaci et al., "Chemotherapyinduced immunogenic modulation of tumor cells enhances killing by cytotoxic $\mathrm{T}$ lymphocytes and is distinct from immunogenic cell death," International Journal of Cancer, vol. 133, no. 3, pp. 624-636, 2013.

[49] E. Vacchelli, Y. Ma, E. E. Baracco et al., "Chemotherapyinduced antitumor immunity requires formyl peptide receptor 1," Science, vol. 350, pp. 972-978, 2015.

[50] A. Sistigu, T. Yamazaki, E. Vacchelli et al., "Cancer cellautonomous contribution of type I interferon signaling to the efficacy of chemotherapy," Nature Medicine, vol. 20, no. 11, pp. 1301-1309, 2014. 
[51] L. Galluzzi, A. Buqué, O. Kepp, L. Zitvogel, and G. Kroemer, "Immunogenic cell death in cancer and infectious disease," Nature Reviews Immunology, vol. 17, no. 2, pp. 97-111, 2017.

[52] G. Kroemer, L. Galluzzi, O. Kepp, and L. Zitvogel, "Immunogenic cell death in cancer therapy," Annual Review of Immunology, vol. 31, pp. 51-72, 2013.

[53] S. Gebremeskel and B. Johnston, "Concepts and mechanisms underlying chemotherapy induced immunogenic cell death: Impact on clinical studies and considerations for combined therapies," Oncotarget , vol. 6, no. 39, pp. 41600-41619, 2015.

[54] N. Casares, M. O. Pequignot, A. Tesniere et al., "Caspasedependent immunogenicity of doxorubicin-induced tumor cell death," The Journal of Experimental Medicine, vol. 202, no. 12, pp. 1691-1701, 2005.

[55] A. Tesniere, F. Schlemmer, V. Boige et al., "Immunogenic death of colon cancer cells treated with oxaliplatin," Oncogene, vol. 29, no. 4, pp. 482-491, 2010.

[56] X. Lu, Z.-C. Ding, Y. Cao et al., "Alkylating agent melphalan augments the efficacy of adoptive immunotherapy using tumorspecific CD4+ T cells," The Journal of Immunology, vol. 194, no. 4, pp. 2011-2021, 2015.

[57] J. Fucikova, I. Truxova, M. Hensler et al., "Calreticulin exposure by malignant blasts correlates with robust anticancer immunity and improved clinical outcome in AML patients," Blood, vol. 128, no. 26, pp. 3113-3124, 2016.

[58] C. Pozzi, A. Cuomo, I. Spadoni et al., "The EGFR-specific antibody cetuximab combined with chemotherapy triggers immunogenic cell death," Nature Medicine, vol. 22, no. 6, pp. 624-631, 2016.

[59] L. Bezu, L. C. Gomes-de-Silva, H. Dewitte et al., "Combinatorial Strategies for the Induction of Immunogenic Cell Death," Frontiers in Immunology, vol. 6, 2015.

[60] C. Pfirschke, C. Engblom, S. Rickelt et al., "Immunogenic Chemotherapy Sensitizes Tumors to Checkpoint Blockade Therapy," Immunity, vol. 44, no. 2, pp. 343-354, 2016.

[61] B. Montico, A. Nigro, V. Casolaro, and J. Dal Col, "Immunogenic Apoptosis as a Novel Tool for Anticancer Vaccine Development," International Journal of Molecular Sciences, vol. 19, no. 2, p. 594, 2018.

[62] A. D. Garg, S. More, N. Rufo et al., "Trial watch: Immunogenic cell death induction by anticancer chemotherapeutics," Oncolmmunology, vol. 6, no. 12, p. e1386829, 2017.

[63] L. Ding, MH. Bailey, and E. Porta-Pardo, "Perspective on oncogenic processes at the end of the beginning of cancer genomics," Cell, vol. 173, pp. 305-320, 2018.

[64] E. J. B. Derissen, J. H. Beijnen, and J. H. M. Schellens, "Concise drug review: Azacitidine and decitabine," The Oncologist, vol. 18, no. 5, pp. 619-624, 2013.

[65] T. Schroeder, C. Rautenberg, R. Haas, U. Germing, and G. Kobbe, "Hypomethylating agents for treatment and prevention of relapse after allogeneic blood stem cell transplantation," International Journal of Hematology, vol. 107, no. 2, pp. 138-150, 2018.

[66] Y. Chen, P. L. McCarthy, T. Hahn et al., "Methods to prevent and treat relapse after hematopoietic stem cell transplantation with tyrosine kinase inhibitors, immunomodulating drugs, deacetylase inhibitors, and hypomethylating agents," Bone Marrow Transplantation.

[67] N. Luo, M. J. Nixon, P. I. Gonzalez-Ericsson et al., "DNA methyltransferase inhibition upregulates MHC-I to potentiate cytotoxic T lymphocyte responses in breast cancer," Nature Communications, vol. 9, no. 1, 2018.
[68] M. Matsushita, Y. Otsuka, N. Tsutsumida et al., "Identification of Novel HLA-A ${ }^{\star} 24: 02-$ Restricted Epitope Derived from a Homeobox Protein Expressed in Hematological Malignancies," PLoS ONE, vol. 11, no. 1, p. e0146371, 2016.

[69] P. Srivastava, B. E. Paluch, J. Matsuzaki et al., "Induction of cancer testis antigen expression in circulating acute myeloid leukemia blasts following hypomethylating agent monotherapy," Oncotarget , vol. 7, no. 11, pp. 12840-12856, 2016.

[70] M. L. Stone, K. B. Chiappinelli, H. Li et al., "Epigenetic therapy activates type I interferon signaling in murine ovarian cancer to reduce immunosuppression and tumor burden," Proceedings of the National Acadamy of Sciences of the United States of America, vol. 114, no. 51, pp. E10981-E10990, 2017. 


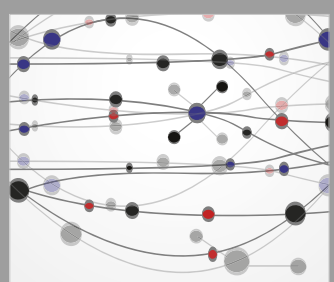

The Scientific World Journal
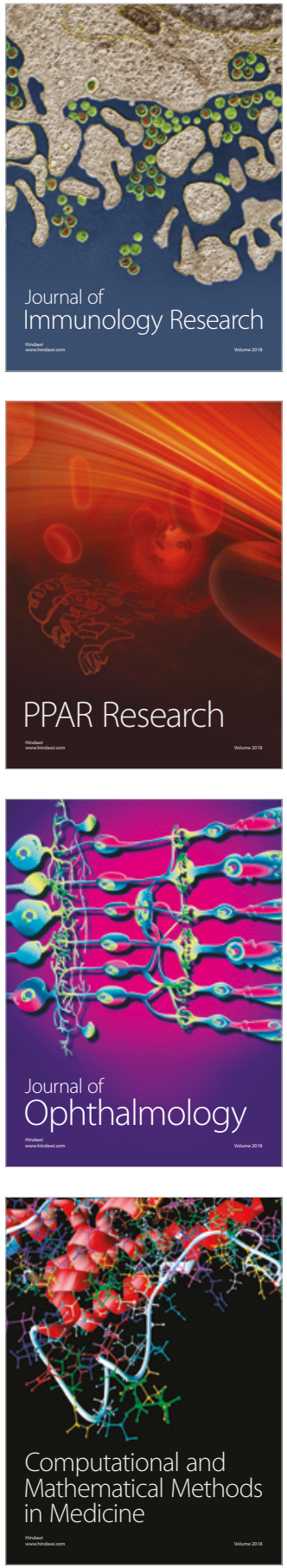

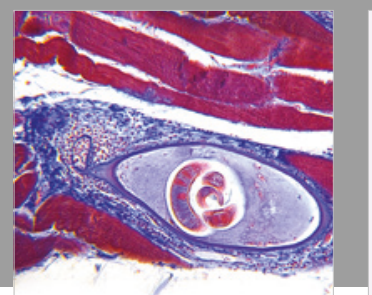

Gastroenterology Research and Practice

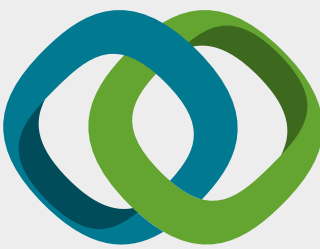

\section{Hindawi}

Submit your manuscripts at

www.hindawi.com
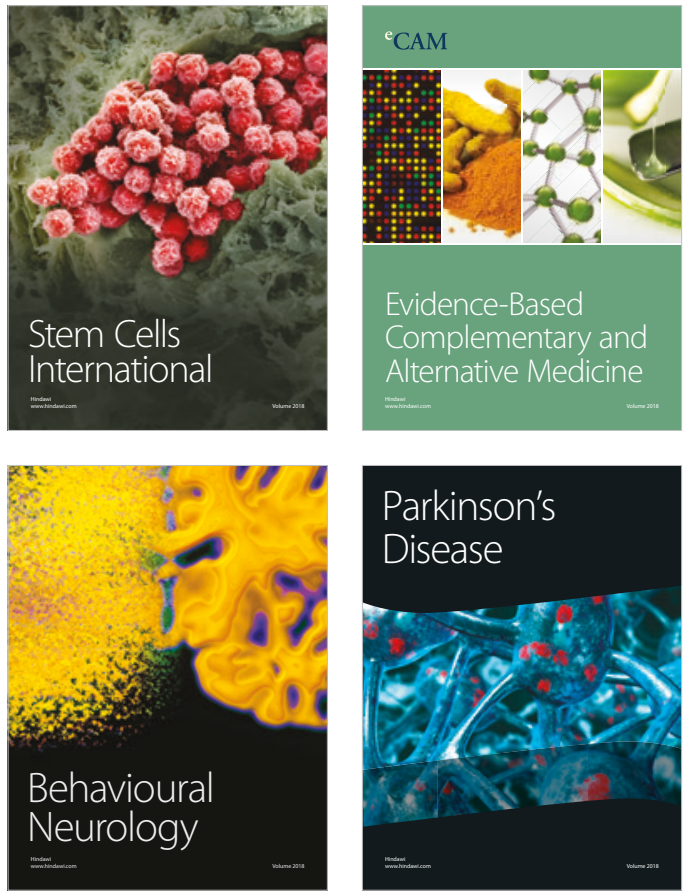

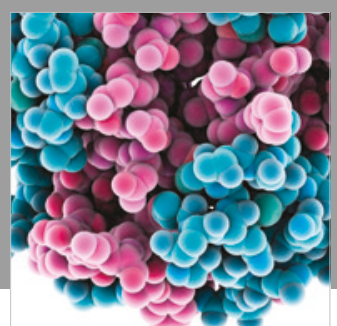

ournal of

Diabetes Research

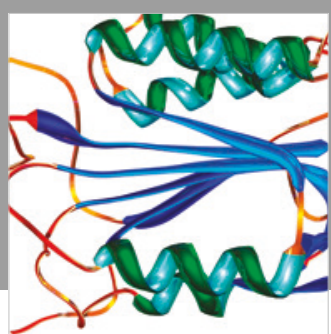

Disease Markers
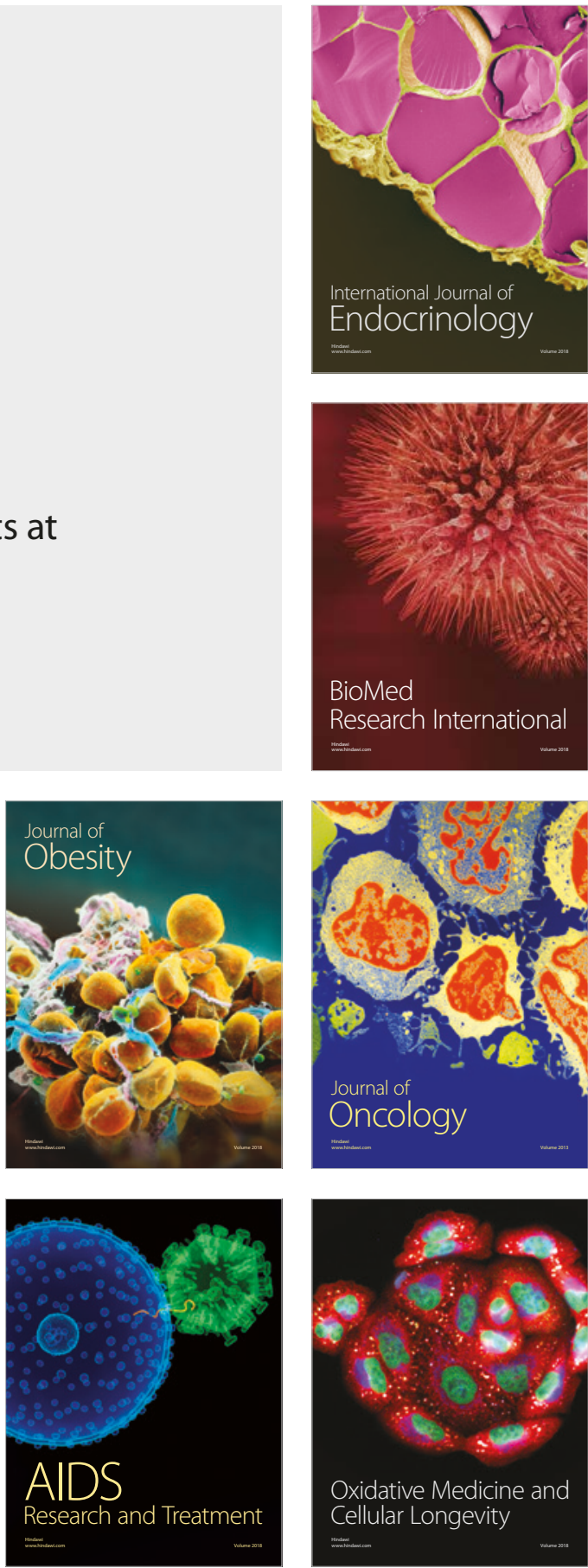